\title{
The Ten Million Euro Question: How Do Innovation Intermediaries Support Smart Specialization?
}

\section{Matjaz Vidmar}

Science, Technology and Innovation Studies, The University of Edinburgh, United Kingdom

matjaz.vidmar@ed.ac.uk
CroEconSur

Vol. 21

No. 2

December 2019

pp. 37-84

Received: October 22, 2018

Accepted: July 2, 2019

Research Article

doi:10.15179/ces.21.2.2

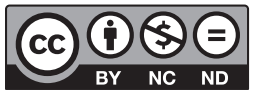

\section{Abstract}

Smart Specialization Strategy (S3) has become a dominant regional economic development field with significant policy traction, in particular within the European Union. However, questions are being raised about its operationalization and a gap has been identified with respect to the role of innovation intermediaries' interventions in support of the developing regional-sectoral innovation systems. In particular, reasons for diverging policy approaches of "niche specialization" versus "regional advantage" in comparable situations should be examined to illuminate the contextual factors impacting the interpretation of the intermediaries' mandates. In this paper, the cases of two leading investments in innovation intermediation in the emerging New Space sector are analyzed (Space-SI and Higgs Centre for Innovation) in two EU NUTS level 1 regions (Slovenia and Scotland), which 
were previously peripheral players in this technological domain. In particular, using a novel innovation intermediation interventions' classification, this paper identifies the difference between research and development (R\&D) and business development (BD) support foci in the two locales, noting some of the contextual factors associated with them and arguing for the long-term balancing of the two approaches.

Keywords: smart specialization, innovation intermediaries, innovation policy, innovation networks, New Space industry

JEL classification: O38, L53

\section{Introduction'}

The European Union's National/Regional Innovation Strategies for Smart Specialization policy (European Commission, 2014), which emerged from regional innovation systems insights in economic development (DG Research Expert Group on Constructing Regional Advantage, 2006), is currently being integrated into a broader innovation policy context. The conceptual salience of geographically and sectorally bound public policy interventions to stimulate the growth of new business activity and complementary diversification of innovation is seen as an important pathway to attaining regional competitive advantage through "smart" prioritization of investment (Camagni \& Capello, 2013; Asheim, 2019). The implementation of smart specialization strategy (S3) policy in practice is proposed to primarily center on an "entrepreneurial discovery" approach to identifying opportunities for regional economic development (Hausmann \& Rodrik, 2003; David, Foray, \& Hall, 2013), which is partially in contrast to the more

1 Draft version of this paper was presented at the "SmartEIZ conference", held from September 25 to 26, 2018 in Zagreb, within the project "Strengthening scientific and research capacity of the Institute of Economics, Zagreb (EIZ) as a cornerstone for Croatian socioeconomic growth through the implementation of Smart Specialization Strategy". The Institute of Economics, Zagreb implemented the project in partnership with University College London - School of Slavonic \& East European Studies, University Bocconi, Center for Research on Innovation, Organization and Strategy, and Maastricht University, Maastricht Economic and Social Research Institute on Innovation and Technology (UNU MERIT). The project has received funding from the European Union's Horizon 2020 research and innovation program under grant agreement No. 692191. 
stakeholder-driven economic analysis and geographical prioritization associated with the previously established economic policies based on constructing regional advantage (Barca, McCann, \& Rodríguez-Pose, 2012; Vanthillo \& Verhetsel, 2012; Boschma, 2013). However, the implications of various contextual factors of either of the two S3 approaches to geo-sectoral innovation policy development on its operationalization is currently under-studied, especially with respect to onthe-ground implementation through various organizations.

In particular, though some research in the role of institutions ${ }^{2}$ to set and govern the S3 policy has been carried out (McCann \& Ortega-Argilés, 2014; RodríguezPose, di Cataldo, \& Rainoldi, 2014; Grillitsch, 2016; Morgan, 2017), less is being said about the on-the-ground deployment of interventions delivering S3 operationalization, which is a key capacity required, and organizations that deliver them (Karo \& Kattel, 2016). Specifically, S3 literature is almost entirely devoid of mention of innovation intermediaries, seen by many innovation systems' analysts as key vehicles to deliver "institutionalized learning", which is at the very core of RIS conceptualization (Cooke, Gomez Uranga, \& Etxebarria, 1997). Moreover, innovation intermediaries are currently the subject of extensive analysis and debates in the broader economic development literature (Katzy, Turgut, Holzmann, \& Sailer, 2013; Nilsson \& Sia-Ljungström, 2013; Kivimaa, 2014; Kokshagina, Le Masson, Kazakci, \& Bories, 2015; Mgumia, Mattee, \& Kundi, 2015; Kerry \& Danson, 2016; Lukkarinen et al., 2018; Vidmar, 2018). Hence, a critical gap has emerged in understanding how innovation intermediaries are deployed to support S3 policy. This is especially problematic with the increasing awareness that the challenges for S3 policy are now predominantly in its implementation, which could be alleviated by capacity building through policy interventions (Kroll, 2019). Hence, using the state-of-the-art understanding of innovation intermediation in order to study its current use, and develop proposals for its

2 RIS and S3 literature, as well as innovation studies more broadly, mainly define "institutions" as a mix of formal and informal social structures (Rodríguez-Pose, 2013), which sometimes obscures the differences between intangible "sets of common habits, routines, established practices, rules, or laws" and their manifestation through "formal structures with an explicit purpose" (Edquist \& Johnson, 1997). For clarity, the term "institutions" is used here as in the cited texts, whilst "organizations" will be used in this paper when specifically referring to the actors. 
improvement, within the $S 3$ context is a vital advance in supporting further $S 3$ policy-making.

To that aim, this paper draws upon two carefully selected case studies of two different instances of innovation intermediation, supported by significant direct public investment, in two different yet comparable geopolitical contexts. The rationale behind this work is to explore the different mechanisms used to deliver smart specialization strategy-type policy through innovation intermediation. The interventions examined focus on supporting the economic development of high-tech (New) Space industry in regions that were previously peripheral in this domain, namely in Slovenia and Scotland. Though the geographical conditions in the two countries are somewhat similar, the (historical) socio-economic and political context is not. This led to different prioritization in government investment in the development of this industry, responding not only to the existing economic and research activities and infrastructure, but also to innovation policy path-dependency related to socio-political frameworks (Farole, Rodríguez-Pose, $\&$ Storper, 2010).

On one hand, in Slovenia, a 10 million euro investment (supported by the EU structural funds) led to the creation of the Centre of Excellence (CoE) Vesolje-SI (Space-SI), a university-led applied research program, in 2009, and on the other hand, in Scotland, a 10.7 million pound UK government investment in 2013 funded the development of the Higgs Centre for Innovation, a business incubator and innovation facility. Though the development of both of these innovation intermediation projects is still ongoing, their inception, implementation, and positioning illuminate a key challenge in direct intervention in an economic sector - whether to focus on research and development (R\&D; i.e., creating new products or services) or business development (BD; i.e., creating and accelerating new firms). Understanding these different approaches better will help develop more coherent innovation policy positions on smart specialization strategies since it involves critically examining the emerging "policy mixes" "[...] by focusing much more effort on understanding how implementation, experimentation and 
adaptive learning affect the impacts of policy interventions driven by real goals" (Flanagan \& Uyarra, 2016, p. 185).

Deploying a recently developed innovation intermediation model (Vidmar, 2018), this paper examines the differentiation in adopted mechanisms between the two cases depending on the (politically) defined intermediation focus. Furthermore, by looking at the set-up of the intermediaries, their primary activities, and target users, the proposed model was developed further by exposing a key systematic combination of different classes of interventions within the overall distinction of R\&D and BD support foci. Finally, the societal and political environment leading to the establishment of these two centers is briefly examined and discussed in the context of a divergent implementation of innovation policy, including smart specialization, and its potential pitfalls.

\section{Defining and Implementing Geo-Sectoral Innovation Policy: The Role of Innovation Intermediaries}

\subsection{Innovation Policy in EU and Smart Specialization Strategy (S3)}

Smart Specialization Strategy (S3) has emerged as a flagship (European) policy framework linking economic geography research with innovation and entrepreneurial (eco)systems literature (McCann \& Ortega-Argilés, 2015). The aim of $S 3$ is to stimulate economic development by focusing investment across different regions into specific and distinct opportunities and thus establishing a regional competitive advantage, both within common market frameworks (such as EU) as well as in global competition (OECD, 2013). This focusing is intended to establish economic actors with a "related variety" of products and services, or industry "clusters", which are supported by a (local/regional) network of stakeholders, including research organizations, investors, business and infrastructure developers, public sector/government, etc. (David et al., 2013). The 
main premise is for those "smart specializations" to emerge organically/bottomup, with clear policy support, once key opportunities have been identified and “nominated” (Foray \& Goenaga, 2013).

The latter, however, is easier said than done and represents a very contentious issue. Critique has so far focused primarily on the perceived overreliance on "industrial renewal" within existing regional innovation capabilities, which may be preventing the S3 policy to have real transformative effects (Capello \& Kroll, 2016). The main two challenges here are, on one hand, how smart specialization opportunities can be identified, and on the other hand, what (policy) intervention in the sector is appropriate (Foray \& Goenaga, 2013). This paper's premise is that these two issues are very closely linked and that the context and use of the identification process critically define the shape and scope of the final intervention (Hausmann \& Rodrik, 2003; Boschma, 2013; Grillitsch, 2016). Crucially, though many tools for identification are shared across the common policy arena (in our case the EU), the path-dependency (based on past ideological/political commitments) critically co-shapes their use and leads to a very different set of policy mixes, interventions, and outcomes.

In particular, innovation policy's path-dependency leads to different design of S3 policy mixes through contextual factors (Bodas Freitas \& von Tunzelmann, 2008; Asheim, 2013; Valdaliso, Magro, Navarro, Aranguren, \& Wilson, 2014). One of the critical differences noted is between the "vision-driven" innovation policy-making in comparison to a more "analysis-driven" approach (Polverari, 2016). This corresponds to the consequent difference between building the S3 policy process around the more competitive entrepreneurial discovery of niche specializations or the more stakeholder-driven economic development perspectives on establishing regional advantage (Boschma, 2013). These two approaches crucially also demonstrate a split between respective policy-making objectives of creating new opportunities (Foray \& Goenaga, 2013) or addressing systemic failures (Klein Woolthuis, Lankhuizen, \& Gilsing, 2005; Seidel, Müller, Köcker, \& Filho, 2013). Moving forward, Boschma (2013) suggests a balancing 
between these two approaches, built around the inclusion of local stakeholders, and which "[...] should focus on how to enhance true economic renewal, not to pick winners and back them, not to secure local vested interests, and not to make strong local industries stronger" (Boschma, 2013, p. 12).

Here, S3 literature has not engaged much with the role of innovation intermediaries as organizations tasked with the on-the-ground implementation of innovation policy in many governmental and non-governmental innovation policy contexts. Given their critical role in emergent innovation systems, the understanding of their contribution to S3 implementation may be vital.

In order to be able to study these interventions, including how their roles can possibly transcend the binary divide between entrepreneurial vision and analytical construction of competitive advantage in a systematic, structured, and detailed manner, we adopt two key framings. Firstly, this paper limits its study to look exclusively at the delivery of (government) innovation policy through the establishment of innovation intermediaries and their activities. Secondly, we adopt a comprehensive innovation intermediaries' interventions framework as a central analytical tool to ensure consistency across the two case studies. The focus on innovation intermediaries has emerged due to their bridging role between (policy) intentions and (economic) activities, in particular when looking at regional economic development and the pivotal role support for SMEs plays in it (OECD, 2004; Wilson, 2007; Lee, Park, Yoon, \& Park, 2010; Doh \& Kim, 2014). The latter two are also the guiding principles behind the S3 framework.

\subsection{Innovation Intermediaries' Interventions Classification}

The classification and typology of innovation intermediaries' interventions outlined below were devised from a detailed review of innovation intermediaries literature, in particular periodic systemic reviews (Howells, 2006; Dalziel, 2010; Kilelu, Klerkx, Leeuwis, \& Hall, 2011; Nilsson \& Sia-Ljungström, 2013; Kivimaa, 2014; Kim, 2015; Lukkarinen et al., 2018), and combines empirical 
and theoretical insights to summarize the key policy frameworks and operational factors behind the interventions available to support innovation (Vidmar, 2018). The categorization, sub-categorization, and qualification of the various available classes of mechanisms correspond to the level of the development of the sector and firms and organizations within, as well as demonstrate their dependency on certain systemic socio-economic factors. These prototypological drivers were identified as being related to levels of investment and involvement, the strength of vision/mandate, and soft leadership embedded in the intermediaries' programs.

The classification within the scheme (see Table 1) is constructed using two overarching categories of intervention mechanisms, resources provision and deployment of activities, as related to the varying focus of interventions from more broad and systemic (such as investments in resources) to more targeted and specific (such as direct activities to shape a particular vision for development). These categories are split into subcategories of infrastructure, tools, framing, and project, differentiating those with more hands-on types of interventions (such as engaging in projects and developing infrastructure) and those delivered in more hands-off roles (such as sector framing and providing tools for innovation). On the subcategories level, the classification is further split by intervention qualifiers of being either more "physical" or more "social" in character. These overarching qualifiers enable the intermediaries to distinguish between deployment of "hard" and "soft" assets, such as buildings and equipment on one hand, and social capital and thought leadership on the other. 


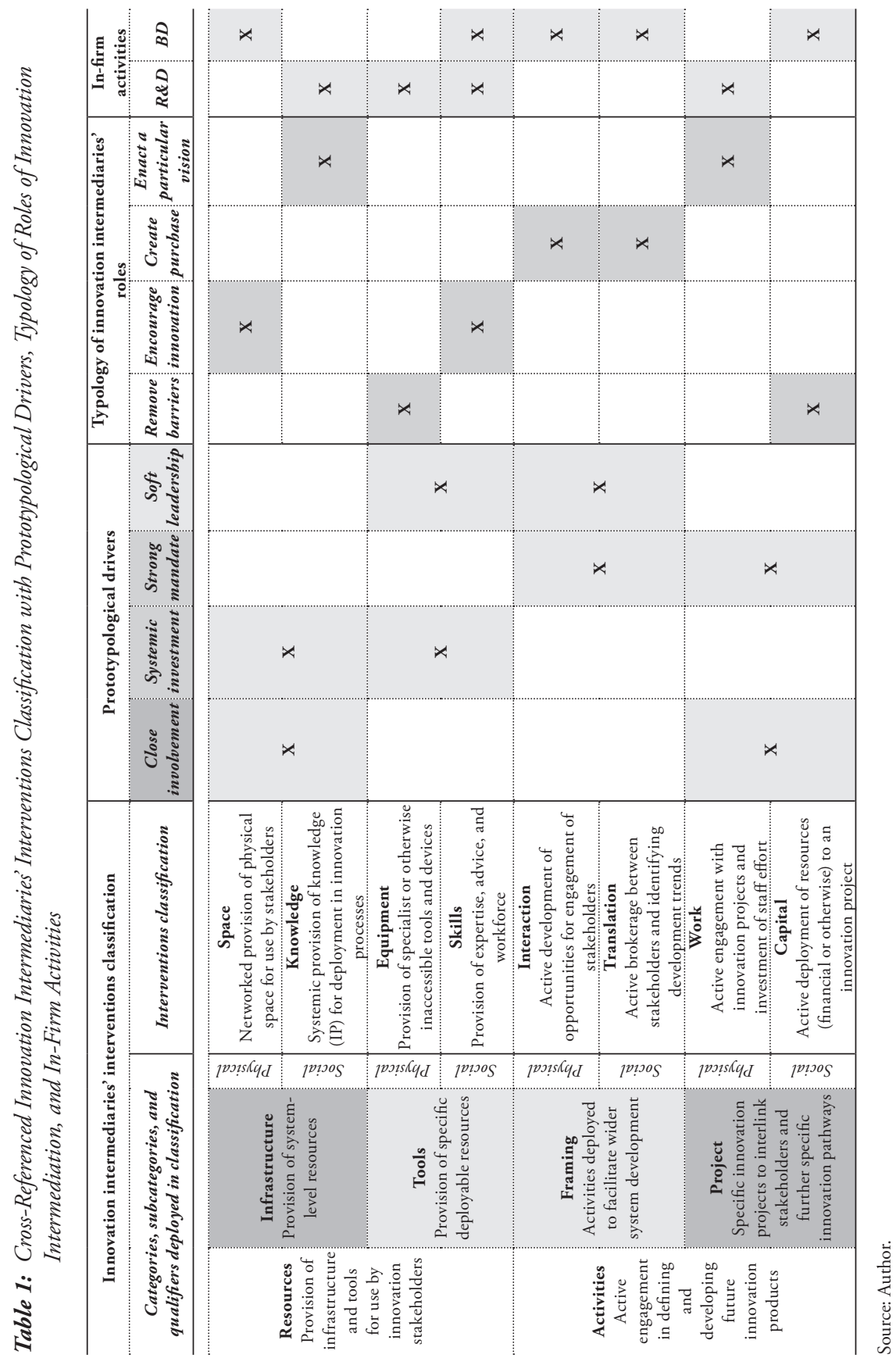


This classification is underpinned by the understanding that most mechanisms available are critically related to the wider system, which is subject to conditions within the target sector as well as in the immediate geographical area in which the innovation support program is executed (Martin \& Scott, 2000; Hannon, Skea, \& Rhodes, 2014). When deploying any analysis of suitable innovation support mechanisms, geographical and sectoral boundaries need to be taken into consideration. In particular, based on extensive analysis of key typological systematizations (Klerkx \& Leeuwis, 2008; Kilelu et al., 2011; Colombo, Dell'Era, \& Frattini, 2015; Kim, 2015), the overarching aims inbuilt into various mechanisms were identified as roughly four-fold: to remove barriers for innovation by providing resources and action to address bottlenecks and challenges; to proactively create conditions encouraging innovation, with the stimulus, promotion, and investment; to create purchase in the innovation, especially by assisting in the development of markets (often external to the sector); and to enact a particular vision for the future of the (economic) activity in a sector (Vidmar, 2018). This roles typology is cross-referenced with the classification (see Table 1). In most cases examined so far, the focus was either on infrastructural investments or specific trendsetting and project work (most usually associated with early stages of an emerging sector/technology) or on more hands-off activities such as providing spaces and incentives for defining trends and easing key skills and equipment shortages (associated with development of commercialization pathways and R\&D consolidation of later stages of development).

However, other analytical prioritizations for understanding the deployment of combinations of the classes of intervention mechanisms are possible. In particular, building on a systematic review of literature, Dalziel (2010) exposed the major difference between "inter-organizational networking activities" and "technology development and related activities". These two categories point to an (at least analytical) split between the systemic (networked) innovation intermediation support (often characterized by the term "brokerage") and more direct processual involvement in new product development. Going one step further, 
the differentiation between the inter-organizational networking and the enabling, supporting, or delivering of specific projects corresponds roughly with the in-firm activities of business development (BD) and research and development (R\&D), respectively. Such a differentiation points to the possibility of a significantly divergent approach to delivering innovation intermediation resources and activities, which could be problematic for achieving robust and sustainable policy impact.

Using this framework to analyze two innovation intermediaries' interventions within a similar parameter space (the same sector/technological domain, similar level of investment, similar position within the innovation policy context, etc.), yet in two different geographical, political, and socio-economic contexts will enable an analytical assessment as to which factors influence the potentially divergent application of intervention mechanisms. The main research question is: how do the two different approaches to S3-type policy implementation, i.e., niche specialization versus regional advantage, lead to divergent on-the-ground innovation intermediaries' interventions and what are the contextual factors in this process as well as its implications? Such understanding can significantly assist in theorizing opportunities and pitfalls in S3 policy design and implementation, in particular as related to the role of innovation intermediaries.

\section{Methodology}

The innovation intermediation model presented above was analytically deployed using comparative case studies approach (Yin, 2009). Two critical instances of innovation intermediation are examined in a geo-sectoral innovation policy context, whereby path-dependency on contextual factors led to different approaches to selection and deployment of interventions. These differences are studied descriptively to establish a correlation with their underlying reasons as well as explore their potential implications (Farole et al., 2010). Given the relatively small size of the two selected geo-sectoral contexts and consequently 
small sample size, qualitative analytical generalization with a pre-determined framework is more reliable than statistical methods (Hartley, 2004).

The research design combines a mixture of secondary data analysis of policy documents and websites (Bowen, 2009), and primary data from longitudinal participatory observation ethnography through events, conferences, and visiting the organizations' workplaces (Darrouzet, Wild, \& Wilkinson, 2009). This was complemented with primary interview and survey data, collected by directly speaking to the staff of the two selected cases (Bryman, 2012). Though only two interviews and two formal surveys were used, given the relatively small sizes of both innovation intermediaries' teams (they both have only three core members) and their close cooperation in filling out the survey questionnaire in particular, the results from interviewing/surveying two members of staff at each organization can be treated as highly reliable, even though the sample size is relatively small.

The document analysis and participatory ethnographic data led to the overarching case studies' descriptions and key identified concepts and trends, whilst direct primary empirical data were used to quantify the key points of divergence between the two cases. On one hand, the interviews were designed to explore the innovation networks of the two intermediaries, asking interviewees to list all partners they work with and subsequently structure those partners according to geographic proximity and basic differentiation between public and private organizations. On the other hand, the surveys assessed the two innovation intermediaries' intervention priorities and the contextual reasons for those - in particular a Likert-scale ranking of their provisions with respect to each of the intervention classes (on a scale of 1 to 5 ) and an overall priority ranking across all intervention classes as well as perceived sectoral needs (in order from 1 to 8) - as well as information about the programs' overall aims and the reasons for them.

Specifically, the secondary and ethnographic data were used to present a brief outline of the set-up of the two innovation intermediaries and their activities so far, including contextualizing some of their challenges presented in the discussion. 
In addition, data collected through the interviews were used to draw up the ego-centric social network analysis plots for each of the studied intermediaries (Crossley et al., 2015), whilst the structured survey data helped frame the analysis of the intervention prioritization within the case study analysis.

\section{S3 - Slovenia, Scotland, and Space: Two New Players in a New Industry}

Under the European Union cohesion funding program, which is one of the cornerstones of S3 implementation, Slovenia and Scotland are considered equally as NUTS level 1 regions $^{3}$, though Slovenia is an independent country, while Scotland is a country within the union of the United Kingdom (UK), though with significant political devolution. In the "Europe of Regions" vision (Jolly, 2006) for the EU future development ${ }^{4}$, the two countries would eventually achieve relative parity of political status and establish primarily endogenous administrative, economic, and social framework conditions, with weaker referential relationship to other institutional levels (in particular nation-states). The two countries are similar in many key parameters ${ }^{5}$ yet diverge significantly in parts of the

3 Following European Union's Nomenclature of Units for Territorial Statistics (NUTS) level 1 (top-level) regional definition framework (Regulation [EC] No. 1059/2003 of the European Parliament and of the Council of 26 May 2003, 2018).

4 On top of the vision of European regionalization being politically challenged in recent years, there is an added point of divergence with possible UK departure from the EU, i.e., Brexit. This paper will assume, however, that the framework conditions during which the intermediaries in question were being developed have to a large extent hinged upon a continuous membership of EU.

5 For example, using Regional Innovation Scoreboard (https://ec.europa.eu/growth/industry/innovation/factsfigures/regional_en; last data available for 2017) summative assessment and comparing aggregated NUTS 2 level data for Slovenia (as level 1 data are not available) and NUTS level 1 data for Scotland, the two countries are in the same category of "strong innovator" though Scotland is in the top band (strong plus), whilst Western Slovenia (including the capital) is considered a "strong innovator" and Eastern Slovenia is in the "moderate plus innovator" category. Key similarities are strong tertiary education and SME collaborations and weak EPO patent applications, whilst critical differences are in trademark and design applications (strong in Slovenia) and strength of scientific publications (stronger in Scotland, though both above EU average). The Regional Innovation Index 2017 for the two regions are 0.52 for Scotland and 0.44 for Slovenia. 
socio-economic, political, and cultural landscape ${ }^{6}$. In recent years, both countries being part of the EU led to a certain degree of legislative homogenization including in aspects of innovation policy (such as S3), though through persistent socioeconomic differences significant divergence in on-the-ground implementation has emerged, which is interesting in exposing contextual elements in applying EU-wide S3 policy.

To remove, as much as possible, the variables between technological domains and sectoral activities, a single sector was picked to be examined, i.e., the New Space sector, which is present and relatively new to both countries. The specific suitability of the New Space sector for this study is further related to three key features:

- The sector's recent emergence, significant growth, and future potential, as well as (global) recognition of competitive advantage;

- Government/policy-makers' recognition of its importance, including, but not limited to, the establishment of innovation intermediaries;

- Its underlying importance for the headline S3 priorities, even though it does not feature strongly in the policy itself.

The latter criteria are particularly interesting as often (too) little attention has been paid so far to the enabling (more upstream) sectors/industries supporting the development of the (generally) more downstream/applied S3 priorities. The

6 Slovenia and Scotland share aspects of historical and contemporary development over the past 200 years, for instance by being part of supra-national political unions (in Slovenia's case these constitutional ties were with the Habsburg Monarchy, the Austro-Hungarian Empire, the Kingdom of Yugoslavia, and the Socialist Federative Republic of Yugoslavia; whilst Scotland is part of the United Kingdom, which underwent a process of division (island of Ireland) and more recently devolution (Wales and Scotland). They also both contain diverse geography (in particular remote mountainous areas and densely concentrated lowlands). Both countries are also politically divided, in Slovenia along partisan lines, whilst in Scotland additionally with respect to position on statehood (independence from UK). Both having an ageing population and having seen much of traditionally strong manufacturing industry deplete, in the 1980s in Scotland and 1990s in Slovenia, they are both now economically based around service industries (centred on their respective capital cities) and agriculture and tourism in the periphery. The differences are predominantly socio-political, due to legacies of the 1990s' transition from socialist economics in the post-second-world-war era in Slovenia in contrast to neo-liberal industrial reforms led by the conservative UK government in the 1980s. There are also broad cultural differences in the educational/intellectual system and overall public service, with the Central-European administration-heavy system inherited in Slovenia in contrast to the more entrepreneurial Anglo-American framework present in Scotland. Through economic and social globalization, these differences are slowly being eroded, which is reinforced by the adoption of the neoliberal economic and social development model by the EU. 
emergence and development of these enabling technologies also pre-date the full roll-out of the S3 framework but are crucially tied into its origins of the geographically-bound sectoral opportunity focus and the emergence of specific lead sectors/technology domains.

\subsection{Smart Specialization in Slovenia and Scotland}

The development of S3 headline priorities in Slovenia and Scotland has a long and varied (as well as temporally different) historical evolution, very different entrepreneurial and innovation landscape, and very different policy instruments. For instance, as evidenced in Scotland (Reid \& Maroulis, 2017) and even more so in Slovenia (Reid \& Stanovnik, 2013), the initial S3 policy roll-out was not applied systematically, heavily depended on prior policy targets and often lacked in cohesion and concrete implementation mechanisms, which were otherwise present in other aspects of (regional) economic development policy (especially in longstanding sectoral priority areas). On one hand, some of these initial issues with S3 policy implementation have been addressed and Slovenia, in particular, is being presented as a case of good practice in adopting the entrepreneurial discovery process that encourages stakeholder ownership of S3 priorities and their governance (Gianelle, Kyriakou, Cohen, \& Przeor, 2016; Karo, Kattel, \& Cepilovs, 2017; Wostner, 2017). On the other hand, the more complex Scottish constitutional position with respect to the UK means that a mixture of regional and national innovation policies apply centered around multi-level "industrial strategies", creating a significantly stakeholder-driven policy framework (Mastroeni, Omidvar, Rosiello, Tait, \& Wield, 2017). This critical difference makes the two countries prime examples for analyzing the organizational implementation of geo-sectoral innovation policy, noting its pre-S3 origins and path-dependencies.

The "official" S3 priorities in Slovenia and Scotland directly overlap somewhat (as highlighted in italics), as in Slovenia they are: smart cities and communities, smart 
buildings and homes, networks for transition into circular economy, sustainable food production, sustainable tourism, factories of the future, health-medicine, mobility, and development of materials as products (Republic of Slovenia, 2017); and in Scotland: creative industries, energy, financial services, food and drink, life sciences, and tourism (The Scottish Government, 2015). Additionally, the "smart infrastructure" strand in Slovenia significantly overlaps with parts of the "energy" priority in Scotland (smart grid, renewables, etc.), as well as "circular economy" and "advanced manufacturing" being emphasized in both frameworks.

In contrast, one of the key enabling technologies supporting the identified S3 opportunities ${ }^{7}$ has a much more homogenous trajectory between the two countries and is present in the overlapping priority areas, in particular in agri-food and smart infrastructure, as well as in advanced manufacturing/factories. This area combines remote environmental monitoring through the use of space/satellite data for Earth observation and new high added value engineering, including space hardware - i.e., the New Space. This sector emerged in the mid-2000s in both cases (and globally), though in Scotland it evolved from entrepreneurial activities and organic knowledge spill-over only attracting more substantial policy investment later (after 2010), whilst in Slovenia, the innovation intermediation interventions were deployed to kick-start the sector earlier (in 2009) and are only now engaging with the wider entrepreneurial landscape (since 2015). This demonstrates a very different path-dependency for intervention mechanisms, which are in more detail examined below, based on two flagship case studies of the two largest innovation intermediation investments, the Slovenian center Space-SI (2009) and the Scottish Higgs Centre for Innovation (2013).

\section{2 (New) Space Sector}

Analysis of the space sector is ordinarily split into two main areas: upstream (hardware and data acquisition) and downstream (data processing and applications)

7 Space as a key enabling technology for $\mathrm{S} 3$ opportunities has also been identified in many other regions, for instance, Lazio (Lombardi, 2016). 
(OECD, 2007, 2011, 2014). There are three key types of technologies, and consequently, products/services involved: Earth observation, (GIS) navigation, and telecommunications and broadcasting (Satellite Applications Catapult, 2014; Space IGS, 2014). The sector's historical development is in its 3rd phase - after the initial state monopoly (1st phase), the technology was commercialized by large multinational corporations (2nd phase), and is now being democratized through innovation and entrepreneurship as the previously complex and expensive hardware becomes smaller, more standardized, and cheaper (Space IGS, 2011). This is sometimes referred to as the transition from "classical" towards "New Space" (Adlen, 2011).

This is particularly visible as:

- Increased commercial tendering for government programs, in particular with regards to "services" such as launch capability, operations management, etc. Though the corporate monopolies are still dominant (in the "classical market"), disruptive technologies are making this area much more competitive - with entrants such as SpaceX (working on reusable launch rockets) and Virgin Galactic (space tourism). These are not really present (yet) in either Scotland or Slovenia as they develop around strong governmental space policy, which neither country has ${ }^{8}$.

- Establishment of the smaller satellites market $(<500 \mathrm{~kg})$, operating outside the traditional paradigms (cheap, rapidly-prototyped, and mass-produced products based on consumer electronics and composite materials). Scottish SMEs Clyde Space and Alba Orbital are significant players in the smaller (nano- and pico-) end of this emerging market and R\&D in this area is also present in Slovenia (e.g., NEMO-HD and TRIsat satellite projects), though mainly in intermediaries (Space-SI) and research organizations (University of Maribor), respectively.

8 The UK in particular has developed space policy as part of its science and industrial/innovation policies rather than a full-blown space program seen in most other large space "powers" (Vidmar, 2019c). 
- Significant expansion of space data market, driven by the high-tech tail end of the development of data science and global connectivity, creating data storage, analysis, and access to information on an unprecedented scale; being extensively supported by open data policies of major Earth observation programs, in particular the EU-funded Copernicus program (Berger, Moreno, Johannessen, Levelt, \& Hanssen, 2012) and US National Oceanic and Atmospheric Administration's Landsat (Woodcock et al., 2008). Slovenian and Scottish SMEs have been recognized as competitive leaders on the European level ${ }^{9}$.

\subsection{The Case Studies' Context}

Slovenia has a long history of involvement with astronomy, space science, and space exploration, from Jozef Stefan's research in black body radiation to space travel pioneers like Herman Potocnik Noordung, who was at the heart of the 1920s' "first shot at space". More recently, Slovenian-born scientists and engineers were involved in several key international projects, though it is only in the past couple of decades that globally important research and applications have been developed in Slovenia itself. In addition to world-leading research being conducted at Slovenian universities, for instance in space medicine, Slovenian companies supply state-of-the-art components and materials to the global space industry. Though the number of spin-offs and SMEs is still relatively low (10-15 in 2018), most of them are strong exporters and internationally competitive in their niche areas (Bušljeta, 2019; Uranjek, 2019).

Furthermore, many interdisciplinary centers and groups have been established within the academia in the past decades to examine opportunities to develop independent capabilities and space assets, in particular in tracking and ground stations, small satellites and components, and data analysis and applications. Slovenia is also home to initiatives in the field of contextualizing space science and

9 For instance, Slovenian SME Synergise and Scottish SME Astrosat both won the European Space Agency's Copernicus Masters competition for best EO data application (ESA, 2019). 
technology through art and humanities, both in research and practice, with an extensive program of activities supported by key international space agencies and players, including NASA, ESA, and Roscosmos (Russian Space Agency) (Leach, 2014). Though still without a national space agency or a state-backed space program, since 2016 Slovenia is an associate member state of ESA (European Space Agency).

Scotland, too, has a long and rich history of astronomy and space science, with notable people and institutions leading key global developments for centuries. In more recent times, the activities particularly relevant for (New) Space industry are linked to the commercialization of satellite broadcasting and telecommunication technologies, where Scotland has played a significant role within the broader UK effort (i.e., BskyB, Inmarsat, etc.). Furthermore, over the past 5-10 years, Scotland has become widely known around the world as a "New Space hub" with "Space Glen" and "Agile Space" brands, and with leading upstream and downstream New Space primes being established (Scottish Business Insider, 2018). This developed initially (in the 2000s) from three leading clusters of research and economic activity in Glasgow (hardware), Dundee (electronics), and Edinburgh (data analytics) and in total some 20-25 SMEs (in 2018). Most of these firms are export-oriented and internationally competitive (Macdonald, 2017, 2019).

These SMEs benefited from a long-standing historical legacy of science, engineering, and venture creation in Scotland and in the UK, as well as regional and national investment in science, $\mathrm{R} \& \mathrm{D}$, and innovation, as part of the broader (regional) economic development vision. For instance, (aero)space is a key target sector for Scottish Enterprise, the regional economic development agency, roughly following a UK policy to attract a 10 percent global market share by 2030 (Space IGS, 2011), of which 10 percent (or 1 percent of global) should be in Scotland (London Economics, 2015). This work expanded significantly in the past decade, from participating in global aerospace B2B supply chains to the sector achieving relative maturity, by consolidating an entire New Space value chain within Scotland, such as in the attempts to institutionalize the regional 
ecosystem with the establishment of the (industry-led consortium) Agile Space Group in early 2017 (Agile Space Group, 2017).

\section{From Policy to Practice: Innovation Intermediaries and Interventions}

We now turn to the two case studies of innovation intermediation within Slovenia and Scotland; in particular, the way in which the two intermediaries were set up, what kind of objectives were proposed, and what kind of interventions were planned/delivered, including briefly examining who their beneficiaries were. This has been drawn from digital and physical document analysis (websites [see Figure 1 for illustration], brochures, leaflets, talks/presentations, records of public statements, etc.) and primary data collection (interviews, discussions, participant observations, etc.). The resulting analysis has also been validated by the relevant representatives of the centers in an ongoing process of open exchange of data, ideas, and findings/conclusions.

Figure 1: Space-SI and Higgs Centre for Innovation Website Captures with Headline Information and Current News about the Work at the Two Centers

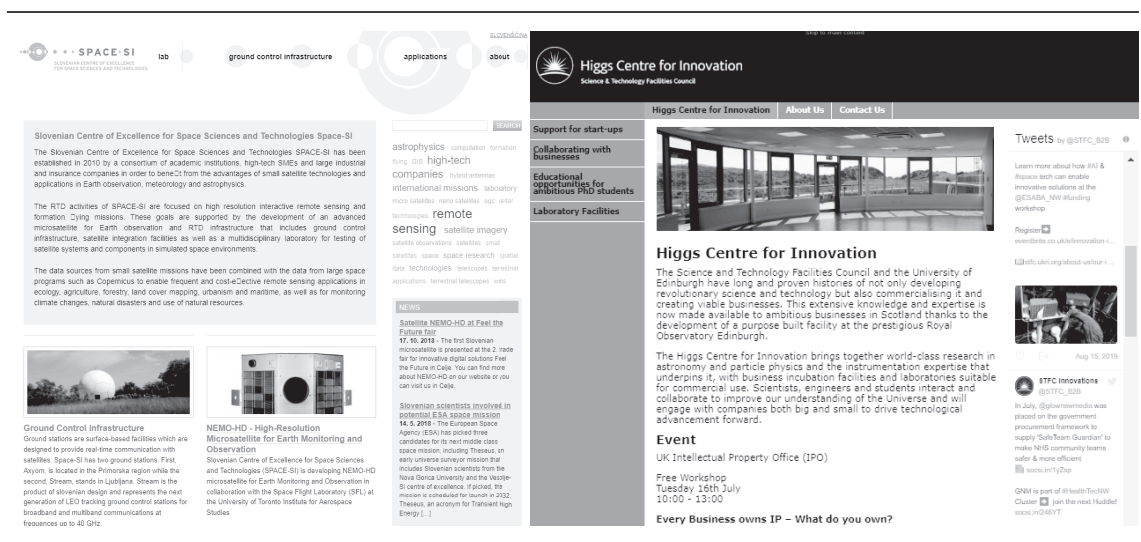

Sources: Space-SI (http://www.space.si/en/) and Higgs Centre for Innovation (https://www.roe.ac.uk/higgscentre/). 


\subsection{A Cradle of Applied Research (Slovenia): Centre of Excellence Space-SI}

The Centre of Excellence (CoE) Vesolje-SI or Space-SI was established in 2009 by a consortium of 11 partners (5 academic, 5 industry, and 1 lead-user) responding to a call by the Slovenian Ministry for Economic Affairs, which led to the establishment of eight different sectoral CoEs, each backed by a 10 million euro investment (85 percent from EU Regional Development Fund) over the first four years of operation (2009-2013). Beyond that, the CoEs were expected to operate the same regime of research and development without governmental support for another five years.

In addition to engaging with policy-makers and other stakeholders in shaping the Slovenian response to various developments and trends in the European and global space industry (i.e., "New Space” and "Open Space”), the applied research nature of the center meant it formed three lead groups of work/projects, covering the whole (New) Space sector value chain:

1. Satellite development and testing environment (upstream), in particular by developing the indigenous capability for satellite design and testing, whilst integrating into a global network of upstream space developers, in particular by working with lead partners from Canada, and symbolically putting Slovenia on the space countries map.

2. Mobile ground station and signal transmitting systems development (midstream), working, in particular, to bring together and activate a host of Slovenian businesses with various technological capabilities, but without prior interest or involvement in space industry, also leading to a market poleposition.

3. Space data applications (downstream), specifically by working with already well-established networks and public and private actors within Slovenia (in particular ZRC-SAZU) and establishing a public profile for space data applications. 
In particular, in the case of the ground station, a surveyed member of staff remarked: "With revolutionary advances in the small satellite sector, especially related to the emerging mega constellations, SPACE-SI saw a need to design the ground station that will be able to track a large number of low powered satellites, many of them cube-sats, that will produce huge amounts of fragmentally generated data" (emphasis added).

In doing so, Space-SI pursued at once three complementary models of innovation, with:

a) Knowledge absorption and technology transfer from global networks;

b) Development of a related variety cluster of actors;

c) Bottom-up open innovation with a broad stakeholder base.

Such broad value chain engagement and tri-partite approach to innovation are highly unusual in a single small-to-medium sized (public) organization and are more akin the behavior of either multinational corporations or public agencies (with much broader remits and deeper budgets).

At the moment, the initial (pre-prescribed) phase of the CoE's development is nearing completion, and the center is looking at ways in which it can most effectively continue and expand its activities, in particular in terms of commercialization of products, which was so far not permitted under the terms of the EU/government investment. In line with the observation above, the two competing conceptualizations of the future set-up and modus operandi are:

1. Spinning out a (group of) SMEs, following similar models from abroad (cases to note are Silicon Valley and Scottish Agile Space model), or

2. Developing a new "business paradigm" of critical infrastructure R\&D and commercialization for the public good (and also learning from experiences of world-leading research centers, such as Surrey Space Centre). 


\subsection{A Business Launchpad (Scotland): Higgs Centre for Innovation}

Backed by a 10.7 million pound direct UK government investment administered by the Science and Technology Facilities Council (STFC), one of UK's main funding bodies for natural sciences research, the Higgs Centre for Innovation at the Royal Observatory Edinburgh (ROE) was announced as a new business incubation and innovation facility in 2013. The center was established at the nexus of three contexts: the ROE campus was the only one of the STFC-run national laboratories without such a facility, the UK wanted to celebrate the receipt of the Nobel Prize in Physics by Edinburgh-based Peter Higgs, and the space industry in Scotland and the UK has become a prominent emerging industrial sector. In particular, after its initial emergence in the (late) 2000s on the back of several successful entrepreneurial start-ups and university spin-offs, the budding Scottish New Space sector was identified as a key development area (by both the UK and Scottish government) and found to be lacking access to physical space, as well as more targeted activities to disperse skills.

Hence, the project proposed to create a regional nano-satellite and space data application incubator, closely linked to STFC's UK Astronomical Technology Centre, based at the ROE. According to the aims of the program, the Higgs Centre for Innovation is planned to:

- "House and incubate up to 12 high-tech start-up businesses

- Support them with a comprehensive package of business training, technical advice, and access to equipment and facilities

- Provide PhD students with direct experience of entrepreneurial environments

- Offer to SMEs access to specialist labs and test facilities for micro/nanosatellites housed within dedicated clean-rooms" (STFC, 2015).

This is related to its core mandate to "create new market opportunities", through "enabling start-ups to translate fundamental research into wider commercial impact" by "applying business incubation best practice to big data and space 
technology" (STFC, 2013). Importantly, the Higgs Centre for Innovation is not a stand-alone project, as it is run in collaboration with the University of Edinburgh (especially its Institute for Astronomy, also based at ROE) and is "[...] part of the European Space Agency (ESA) BIC UK*, CERN BIC, and UK Space Agency (UKSA) BIC networks" (STFC, 2018).

The main part of the investment included the construction of new offices and laboratories and acquisition of associated equipment. As such, it required a significant financial investment, in this case relying on public funding, which was justified on the basis of a pre-existing emergent ecosystem (including a critical mass of companies) and a significant social capital vested in the STFC (most often built on past track record and/or existing infrastructure). Specifically, this was acknowledged as "the new centre will build on the success and proven track record of similar models seen in the STFC ESA and CERN Business Incubation Centres as well as the Innovations Technology Access Centre” (STFC, 2013).

Crucially, due to the significant amount of public funding involved in this program, the steering vision for the center is far more modest, in line with science and innovation policy conceptualization of the state as a "neutral broker" (Egbunike, 2016) providing more general support (Bodas Freitas \& von Tunzelmann, 2008). Also of note is the extensive start-up and spin-out focus, engaging with the early-stage innovation process and emerging opportunities and markets, with specific support primarily for commercialization and business development, with secondary roles in knowledge and technology transfer and sectoral integration. The center was completed and opened in May 2018 and has within its first year (as of May 2019) attracted five incubate SMEs and held several industry networking and knowledge dissemination events in its dedicated lecture space. 


\section{Discussion: Ten Million Reasons for Specific Design and Application of Interventions?}

Clearly, both of the above organizations deliver support in the research and development $(\mathrm{R} \& \mathrm{D})$ and business development $(\mathrm{BD})$ domains, with the intention to support or establish new commercial opportunities. This is primarily oriented to link academia and regional business ecosystems, with a particular focus on SMEs. However, looking back at the proposed identification of the four main objectives of innovation intermediaries' interventions, a clear divide has emerged between the two studies, in that the Slovenian case is predominantly focusing on enacting a vision, whilst the Scottish one is more focused on enabling innovation. Though these are contingent indicators only, the staff's survey data ranking of their interventions classification, presented in Figure 2, also points to significantly different prioritization of various available types of interventions, i.e., stronger performance on work, knowledge, and skills for Space-SI, whilst the Higgs Centre for Innovation is more focused on space and skills. The ranking contained here is subject to change as operational activities (and related policies) are in a constant state of flux. Using the perspective of the prototypological drivers, both intermediaries are strong in providing "systemic investment", and the Slovenian Space-SI is also enacting a "strong vision/mandate". This set-up of the two intermediaries strongly suggests that the Slovenian Space-SI center is predominantly focused on applied research (or R\&D), whilst the Scottish Higgs Centre for Innovation primarily supports business development (BD). 
Figure 2: Analytical Ranking of Key Innovation Intermediaries' Intervention Mechanisms Deployed in the Two Case Studies Using a Likert-Scale-Based Methodology and Source Data from Surveys

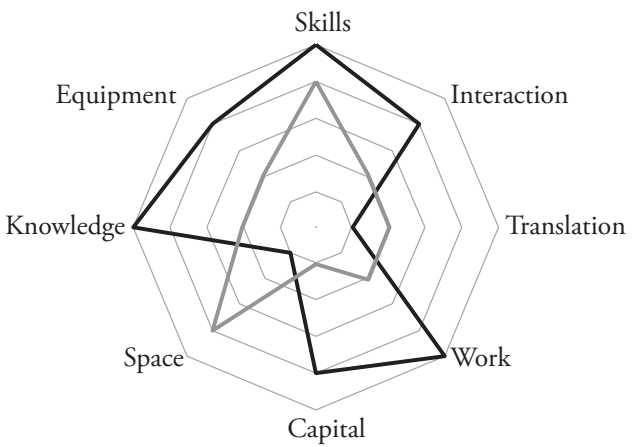

— Space-SI - Higgs Centre for Innovation

Source: Author.

This division is also clearly evident when examining the intermediaries' respective ego-centric networks, containing the main organizational partners supporting and participating in the intermediaries' programs. Specifically, as seen in Figure 3, Space-SI's network is dominated by private partners mainly within the city and country of operation (Slovenia), whilst the Higgs Centre for Innovation's network is heavily dominated by public partners, equally distributed in the city (Edinburgh), country/region (Scotland), and state $(\mathrm{UK})^{10}$. This is consistent with the findings from across the wider innovation networks in both countries (Martin, Pahor, \& Jaklič, 2015; Vidmar, 2019b). The critical distinction here is beginning to emerge in terms of the organizational set-up, linked to the aims of the two intermediaries' programs. In the R\&D-focused Slovenian case, the focus is on applied projects between the main research organization (University of Ljubljana) and its already established SME partners, which already have established roles

10 In addition, the associated qualitative data for the Higgs Centre for Innovation point to a particularly strong presence of geographically fluid partners, spanning city-region/country, region/country-state, and state-Europe boundaries by having local presence within the smaller geography, but a wider influence over the bigger one - a good example here is Scottish Enterprise, which has significant offices in the city of Edinburgh and operations across (Central) Scotland. 
within the (business) ecosystem, but they lack concrete new products or services development incentives. Importantly, these private players were also involved in the set-up of the center itself, as mentioned in the survey: "The Slovenian Centre of Excellence for Space Sciences and Technologies SPACE-SI has been established in 2010 by a consortium of academic institutions, high-tech SMEs and large industrial and insurance companies in order to benefit from the advantages of small satellite technologies and applications in Earth observation, meteorology and astrophysics" (emphasis added).

Figure 3: Ego-Centric Social Network Graphs of the Two Studied Innovation Intermediaries' Networks, Space-SI (left) and Higgs Centre for Innovation (right)

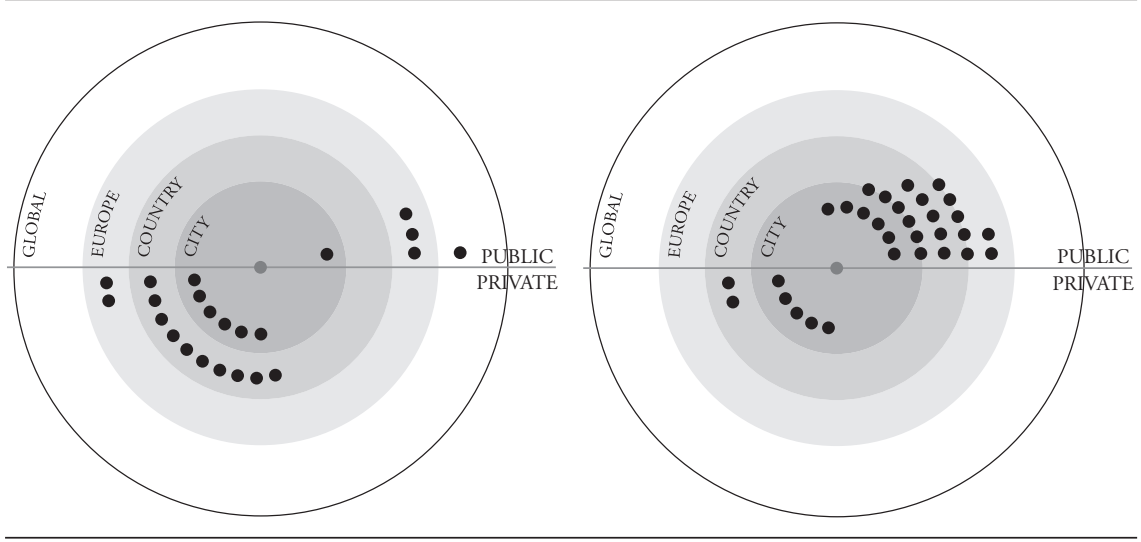

Source: Author.

Conversely, in the Scottish case, the impetus is on building business development capabilities, supported by inter-organizational networking and learning, thus the Higgs Centre for Innovation relies more heavily on other intermediaries, research organizations, and funding/development agencies whose resources and capital can be leveraged in this arena. In the survey responses, they mention that: "There was a real block between academic thinking and the commercial world that still needs to be broken down. The programmes we offer are meant to make these easier. [...] To make links between academic research and the commercial world. 
Furthermore, to derisk innovation as both can be challenging for pushing ideas out to a wider market" (emphasis added).

Furthermore, the difference between these two approaches is highlighted when the two intermediaries' priorities are examined in relation to regional sectoral needs, as seen in Figure 4. On one hand, as with provision ranking across all intervention classes, it becomes clear that Space-SI prioritizes the provision of R\&D-related interventions (classes of work and knowledge) and the Higgs Centre prioritizes business development support (through facilitating interaction and deploying capital). On the other hand, it seems they recognize that in their respective contexts, there is an opposite need for $\mathrm{R} \& \mathrm{D}$ (work) in Scotland and greater need for BD (capital) in Slovenia, and they point to lack of funding as a critical unresolved issue. Both locales are also lacking interventions to establish translation activities and skills in Slovenia and knowledge in Scotland.

Figure 4: Regional Sectoral Needs and Provisions Ranking for the Two Cases

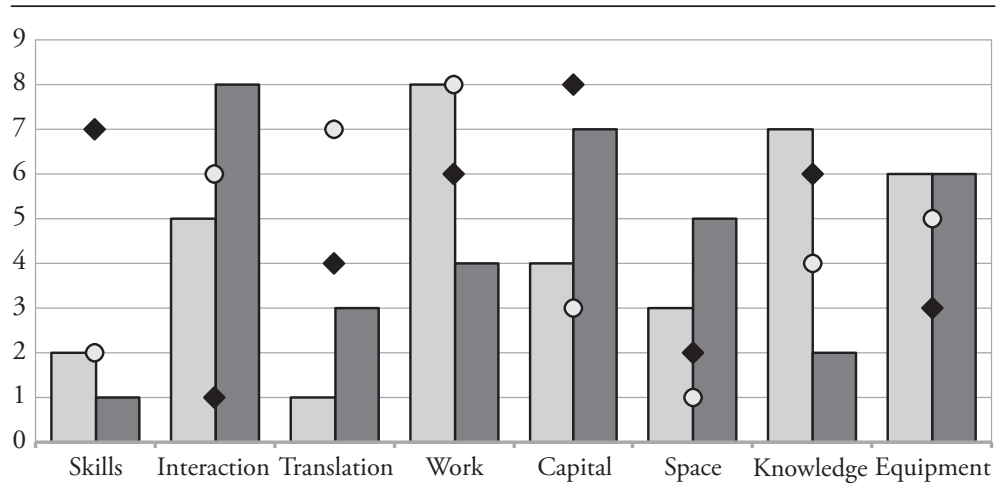

$\square$ Space-SI $\quad \square$ Higgs Centre for Innovation

Needs Slovenia

O Needs Scotland

Source: Author. 


\subsection{Intermediaries' Set-Up: A Question of Politics or Economics?}

The analytical findings above clearly point towards a fundamentally different approach to setting up these two intermediaries, as can already be noticed from statements in policy documents proposing their establishment. The summative comparison of the contextual factors and specific observed policy approach features is presented in Table 2. Specifically, Space-SI was set up as a "center of excellence" with a remit to develop projects leading to applied research solutions in niche areas by integrating diverse actors across the science and business community. In contrast, though the Higgs Centre for Innovation is tapping into a similar policy vision in the UK, as its conceptual roots can be traced back to the Eight Great Technologies paper (Willetts, 2013) and the subsequent investment in Knowledge Transfer Networks and the Catapult network, its focus is firmly in providing resources for start-ups and early-stage SMEs (Kerry \& Danson, 2016).

Interestingly, the Slovenian investment was developed competitively, through a bidding process via an open call, while the Scottish intervention was designed through closed governmental policy mechanisms with industry input. It is then interesting to observe that in implementation, the stakeholder-driven vs. entrepreneurial discovery approaches are reversed, as the Slovenian approach is steering the sector development by creating innovation supply through R\&D project work, while the Scottish one is proposing to satisfy a perceived existing demand for $\mathrm{BD}$ on the back of an already established supply of R\&D ideas, though these might lack some of the edge achieved through more substantial investment.

This study was unable to explore how much of either approach is based on rhetorical political constructs or evidence-based analysis, which would be a critical addition to further substantiate this dichotomy. However, one interesting observation emerged: given the above split between entrepreneurial discoverybased and stakeholder-driven policy process differentiation, it seems that the demand for intervention (originating from universities) within Slovenia was very present, as manifested in the successful consortium of actors shaping the Space-SI 
bid, whilst the Scottish entrepreneurial ecosystem had been politically "steered" to further grow economically and created a regional advantage by governmental investment in building the Higgs Centre for Innovation. Both approaches are crucially linked to delivering the program through supporting knowledge and technology development and transfer from academia.

Table 2: Comparison of Diverging S3 Implementation and Contextual Factors across the Two Case Studies

\begin{tabular}{|c|c|c|}
\hline $\begin{array}{l}\text { Policy approach } \\
\text { Contextual factors }\end{array}$ & Niche specialization & Regional advantage \\
\hline Policy ethos & Entrepreneurial discovery & Stakeholder-driven policy \\
\hline Critical elements & $\begin{array}{l}\text { Policy process, market, } \\
\text { competition }\end{array}$ & $\begin{array}{l}\text { Geography, relatedness, } \\
\text { ecosystem }\end{array}$ \\
\hline Policy action & Facilitating self-discovery & $\begin{array}{l}\text { Removing bottlenecks / } \\
\text { Stimulating innovation }\end{array}$ \\
\hline Case study & Space-SI (Slovenia) & $\begin{array}{c}\text { Higgs Centre for Innovation } \\
\text { (Scotland) }\end{array}$ \\
\hline Policy set-up process & $\begin{array}{l}\text { Competitive negotiation of } \\
\text { interests through open bid }\end{array}$ & $\begin{array}{l}\text { Policy design within } \\
\text { government agencies }\end{array}$ \\
\hline Level of maturity & Low & Intermediate \\
\hline Lead stakeholders & Academia + business & Government/NGOs + academia \\
\hline Lead users & Established firms & Start-ups \\
\hline Main policy principle & "Capitalize on advantage(s)" & "Neutrality" \\
\hline $\begin{array}{l}\text { Intermediaries' intervention } \\
\text { prototypological driver }\end{array}$ & Strong mandate & Systemic investment \\
\hline $\begin{array}{l}\text { Main type of innovation } \\
\text { intermediation role }\end{array}$ & Enacting a vision & Enabling innovation \\
\hline Main support focus & $\mathrm{R} \& \mathrm{D}$ & BD \\
\hline Implementation ethos & "Steering development" & "Satisfying demand" \\
\hline
\end{tabular}

Source: Author.

\section{2 "Scouting the Ecosystem": Alignment of Intermediaries' Intervention to Geo-Sectoral Development}

Partially, these different visions can be explained as responses to different levels of maturity of the emerging New Space sector in the two contexts at the time of the interventions being implemented, with the Slovenian sector less developed than 
the Scottish one. However, it is not clear yet that the Slovenian center accelerated the sectoral development more broadly, since operating within a quite significant set of (regulatory) constraints meant that the commercialization efforts within its program are only now emerging fully (Stare, Bucar, \& Udovic, 2014). Even as the most restrictive barriers (prohibition of commercial exploitation) expired at the end of 2018, lack of access to capital (public or private) is slowing down BD efforts within Space-SI.

Conversely, while (economically) more active, it is equally uncertain how competitive the Scottish sector will be in the mid to long term, as the products and services developed there are comparatively less technologically advanced, since applied research investment is structurally less matched to the specialization areas, as it is funded through other mechanisms. Some of the issues with scope and scale of R\&D funding are currently being addressed through Challenge Funding and place-based City Deals available through the UK's industrial strategy (HM Government, 2017). However, being first to bring solutions to the market and establishing the Agile Space brand (Vidmar, 2019a, 2019c) is ensuring a bigger presence on the global market for Scottish than Slovenian products and services.

Furthermore, the critical question in innovation intermediation intervention is who the users of any given program are (Hyysalo \& Stewart, 2008). Looking at the intervention classifications, the primary target users of the Space-SI program are established companies looking for new opportunities and markets, whereas the Higgs Centre for Innovation is aiming to enter into an already forming market in order to support emerging economic actors (i.e., start-ups). Interestingly, the "strong vision" enacted by the Slovenian center is, hence, embedded in an existing system and the "systemic investment" offered by the Scottish intermediary is supporting and promoting new "visions" for the existing sectoral development. This might yet again be related to the existing sectoral composition, for instance, the more research/less mature economic sector in Slovenia and less research/more economically active sector in Scotland; however, it also exposes a policy approach difference between the two cases. 


\subsection{The Fundamentals: Cultural and Political Differences in Approaching "Impact"}

Crucially, some of these differences can be explained in more societal terms (Farole et al., 2010) through understanding the policy rationales, goals, and implementation approaches as resulting from interaction and tension between different levels and aspects of policy-making and its participants (Blair, 2002; Flanagan, Uyarra, \& Laranja, 2011). In particular, there are clear differences in the political ideology surrounding innovation policy between the two contexts examined in this study. Whilst there is a wide acceptance that supporting innovation is required for continuous and sustainable economic development and growth, the type, level, and mechanisms of policy involvement are considered very differently. In Slovenia, the support is delivered through significant direct investment in the development of specific applications as long as they are predominantly administered within the academia, with commercial applications as a secondary outcome (Bučar, 2015). In the UK, the perceived view is that the innovation support should directly target and involve business interests, with research investment being covered (or not) by separate (science) funding (Edler, Cunningham, Gök, \& Shapira, 2013). This is made very clear not only from the two cases presented here but also when examining other intermediaries and interventions, such as incubation facilities, accelerators, and networks (Slovenian universities' technology parks and incubators, UK-wide KTN and Catapult networks, etc.) (Kerry \& Danson, 2016; Bučar \& Rissola, 2018).

An additional interesting angle here is the diverging definition of scientific "impact" amongst the two contexts, which has a clear economic benefit at its core in the Scottish (UK) one, whilst it is far more flexible and interpretative in the Slovenian case. In particular, BD-type support has been shown to an extent as being more "efficient" (Nishimura \& Okamuro, 2011), which is a critical element of the UK/Scottish policy discourse, more than in Slovenia. Such wider policy narratives are significant co-shapers of the systemic integration of innovation policy (and S3 specifically), which may lead to different emphasis across the 
different environments, including lack of systematic application of EU-wide initiatives (Kroll, 2015; Reid \& Maroulis, 2017).

Following other analyses of innovation policy path-dependent trajectories and capacities in comparable contexts (Valdaliso et al., 2014; Karo \& Kattel, 2015; Karo \& Looga, 2016), one avenue of future research could hypothesize that Scotland has bought into the development of regional competitive advantage earlier, whilst Slovenia had limited exposure to these policies prior to entering the EU (in 2004). Hence, it has not established a strong position on constructing regional competitive advantage and was more easily persuaded into the merits of niche specialization through entrepreneurial discovery as proposed through the S3 policy (Karo et al., 2017; Bučar \& Rissola, 2018). In contrast, Scotland's context of regional devolution within the UK made it more sensitive to the regional competitive advantage opportunities for economic diversification and hence more reluctant to abandon it in favor of more open entrepreneurial discoverybased policy processes (Mastroeni et al., 2017). This proposition would certainly require further empirical (and theoretical) exploration.

Perhaps somewhat worryingly, such different (societal) contexts are clearly shaping (at least part of) innovation policy (Bennett, 2008). Given the institutional obduracy of the organizational momentum behind these path-dependencies (Boschma \& Frenken, 2011; Valdaliso et al., 2014), they can also turn into a self-fulfilling prophecy-like vicious circle, as the perceived precedence of one or the other type of intervention can in the long run deplete the key complementary aspects of a sustainable innovation or entrepreneurial (eco)system (Radosevic \& Myrzakhmet, 2009). On one hand, if $R \& D$ is dominant, commercialization can become neglected, leading to a slow (or even blocked) path to market and loss of competitive advantage. On the other hand, if BD investment is favored by policy, then the level and quality of R\&D can be eroded - note the identified need for more project work and its translation across stakeholders in the Scottish case also leading to a potential eventual loss of competitive advantage as other regions 
with more advanced R\&D activity may emerge in fast-paced high-tech domains (Parikh, 2001).

\section{Innovation and (Political) Agendas: Towards an Answer?}

Hence, the ten million euro dilemma has returned in full force. While one can pinpoint the available options for any new innovation intermediary intervention to deliver on a smart specialization-type policy, the understanding of which (mix of) mechanisms should be delivered depends greatly on the analysis of the (sectoral, geographical, and socio-economic) context ${ }^{12}$. What the two case studies presented here show is that though such decisions should primarily focus on the identified need within the geographically-bound sectoral innovation system they are part of, they also relate to policy path-dependencies, and crucial differences can emerge, which can potentially, in the long run, lead to counter-productive depletion of regional competitiveness.

As such, this paper tentatively proposes that using a comprehensive innovation intermediation framework as outlined earlier (Vidmar, 2018) as part of the policy-making toolkit can improve the strategic thinking beyond the often dichotomous and entrenched "more-of-the-same" approach often adopted, with an aim of balancing R\&D and BD support (Autio, Kanninen, \& Gustafsson, 2008). Though there have been other examples of direct $R \& D$ investment in the New Space sector in Scotland (e.g., UKube-1 in particular, but also SMART Awards funding) and more BD-oriented projects in Slovenia (e.g., the spin-off success of TRIsat satellite co-developer SkyLabs), these are, so far, much smaller investments than the lead projects described in this paper and only further illustrate the importance of combined BD and R\&D support provision on an equal scale (Nishimura \& Okamuro, 2011).

12 This complements currently developed novel statistical methods for $S 3$ policy-making, such as research by Kotnik and Petrin (2017) in Slovenia. 
Having examined these two innovation intermediation examples at an early stage, it is hoped that with longitudinal tracking, further insights into the evolution of these projects will emerge over time. Of particular interest would be more extensive comparative analyses of other (groups and types of) intermediaries and their intervention mechanisms, both within a sector in different regions ${ }^{13}$ and in different sectors within one region. Equally interesting would be a more detailed longitudinal/evolutionary analysis of the application of different policy frameworks for the establishment of innovation intermediation projects and its relationship with the proposed typology. Overall, such further studies, as well as the observations presented here, can assist in bridging the gap between the conceptual vision for smart specialization policy and its operational implementation through innovation intermediation interventions, with opportunities for updating both the theoretical framework and practical recommendations.

\section{Acknowledgements}

Many thanks to all informants and research partners for providing information and validating arising insights. Furthermore, the author gratefully acknowledges supportive and constructive feedback from Dr Alessandro Rosiello, Prof Tim Vorely, Prof Franc Mali, Dr Jennie Olofsson, Dr Niki Vermeulen, Prof Jamie Fleck, and Prof Robin Williams, as well as organizers and attendees of the SmartElZ Conference: "Smart Specialization Strategies: Contemporary Challenges of its Design and Implementation" in September 2018 in Zagreb, especially the very kind, generous, and patient Dr Zoran Aralica, and the two thorough and supportive anonymous reviewers.

This work would not be possible without the generous financial support from the ESRC Pathway Studentship through Scottish Graduate School of Social Science (SGSSS) Doctoral Training Partnership (DTP) [ESRC grant number ES/J500136/1], SGSSS Overseas Institutional Visit (OIV) Grant, Innovate UK - ESRC 2017 Innovation Caucus internship and Science and Technology Facilities Council's ATC Innovations team.

13 Given that tourism is an S3 opportunity area in both Slovenia and Scotland, direct comparative studies such as the one by Daugèlienè and Brundza (2009) are of great value to detailing path-dependency trends and innovation policy processes further. 


\section{Literature}

Adlen, S. (2011). Innovation in the global space industry. London: Imperial College London.

Agile Space Group. (2017). Scotland: Home of Agile Space [Brochure]. Glasgow: Agile Space Group.

Asheim, B. (2013). Smart specialisation - Old wine in new bottles or new wine in old bottles? ERSA conference papers. Retrieved from: https://ideas.repec.org/p/ wiw/wiwrsa/ersa13p476.html

Asheim, B. T. (2019). Smart specialisation, innovation policy and regional innovation systems: What about new path development in less innovative regions? Innovation: The European Journal of Social Science Research, 32(1), 8-25. doi: https://doi.org/10.1080/13511610.2018.1491001

Autio, E., Kanninen, S., \& Gustafsson, R. (2008). First- and second-order additionality and learning outcomes in collaborative R\&D programs. Research Policy, 37(1), 59-76. doi: https://doi.org/10.1016/J.RESPOL.2007.07.012

Barca, F., McCann, P., \& Rodríguez-Pose, A. (2012). The case for regional development intervention: Place-based versus place-neutral approaches. Journal of Regional Science, 52(1), 134-152. doi: https://doi.org/10.1111/j.14679787.2011.00756.x

Bennett, R. (2008). SME policy support in Britain since the 1990s: What have we learnt? Environment and Planning C: Government and Policy, 26(2), 375-397. doi: https://doi.org/10.1068/c07118

Berger, M., Moreno, J., Johannessen, J. A., Levelt, P. F., \& Hanssen, R. F. (2012). ESA's sentinel missions in support of Earth system science. Remote Sensing of Environment, 120, 84-90. doi: https://doi.org/10.1016/J.RSE.2011.07.023

Blair, R. (2002). Policy tools theory and implementation networks: Understanding state enterprise zone partnerships. Journal of Public Administration Research and Theory, 12(2), 161-190. doi: https://doi.org/10.1093/oxfordjournals.jpart. a003528 
Bodas Freitas, I. M., \& von Tunzelmann, N. (2008). Mapping public support for innovation: A comparison of policy alignment in the UK and France. Research Policy, 37(9), 1446-1464. doi: https://doi.org/10.1016/J.RESPOL.2008.05.005

Boschma, R. (2013). Constructing regional advantage and smart specialization: Comparison of two European policy concepts. Utrecht University Papers in Evolutionary Economic Geography No. 13.22. Retrieved from: http://econ.geo. uu.nl/peeg/peeg1322.pdf

Boschma, R., \& Frenken, K. (2011). Technological relatedness, related variety and economic geography. In P. Cooke et al. (Eds.), Handbook of regional innovation and growth (pp. 187-197). London: Edward Elgar Publishing. doi: https://doi. org/10.4337/9780857931504.00028

Bowen, G. A. (2009). Document analysis as a qualitative research method. Qualitative Research Journal, 9(2), 27-40. doi: https://doi.org/10.3316/ QRJ0902027

Bryman, A. (2012). Social research methods. Oxford: Oxford University Press.

Bučar, M. (2015). Stairway to excellence country report: Slovenia. Luxembourg: Publications Office of the European Union. doi: https://doi.org/10.2791/121910

Bučar, M., \& Rissola, G. (2018). Place-based innovation ecosystems: Ljubljana start-up ecosystem and the technology park Ljubljana (Slovenia). Luxembourg: Publications Office of the European Union. doi: https://doi.org/10.2760/717413

Bušljeta, N. (2019). Space technology. Retrieved from: http://www.slovenia.si/ visit/features/space-technology/

Camagni, R., \& Capello, R. (2013). Regional innovation patterns and the EU regional policy reform: Toward smart innovation policies. Growth and Change, 44(2), 355-389. doi: https://doi.org/10.1111/grow.12012

Capello, R., \& Kroll, H. (2016). From theory to practice in smart specialization strategy: Emerging limits and possible future trajectories. European Planning Studies, 24(8), 1393-1406. doi: https://doi.org/10.1080/09654313.2016.1156 058 
Colombo, M. G., Dell'Era, C., \& Frattini, F. (2015). Contribution of innovation intermediaries to NPD process. R\&D Management, 45, 126-146.

Cooke, P., Gomez Uranga, M., \& Etxebarria, G. (1997). Regional innovation systems: Institutional and organisational dimensions. Research Policy, 26(4-5), 475-491. doi: https://doi.org/10.1016/S0048-7333(97)00025-5

Crossley, N., Bellotti, E., Edwards, G., Everett, M. G., Koskinen, J., \& Tranmer, M. (2015). Social network analysis for ego-nets. London: Sage.

Dalziel, M. (2010, June). Why do innovation intermediaries exist? Paper presented at the 2010 DRUID Summer Conference on Opening Up Innovation: Strategy, Organization and Technology, London.

Darrouzet, C., Wild, H., \& Wilkinson, S. (2009). Participatory ethnography at work. In M. Cefkin (Ed.), Ethnography and the corporate encounter: Reflections on research in and of corporations (pp. 61-94). New York, NY: Berghahn Books.

Daugèlienè, R., \& Brundza, A. (2009). Theoretical possibilities of expression of innovation in tourism sector: The case of Scotland and Slovenia. European Integration Studies, 3, 176-183.

David, P., Foray, D., \& Hall, B. (2013). Measuring smart specialisation: The concept and the need for indicators. Retrieved from: https://www.scribd.com/ document/80115599/Measuring-Smart-Specialisation-The-concept-and-theneed-for-indicators

DG Research Expert Group on Constructing Regional Advantage. (2006). Constructing regional advantage: Principles - perspectives - policies. Brussels: European Commission.

Doh, S., \& Kim, B. (2014). Government support for SME innovations in the regional industries: The case of government financial support program in South Korea. Research Policy, 43(9), 1557-1569. doi: https://doi.org/10.1016/J. RESPOL.2014.05.001 
Edler, J., Cunningham, P., Gök, A., \& Shapira, P. (2013). Impacts of innovation policy: Synthesis and conclusion. Nesta Working Paper No. 13/21. Retrieved from: https://media.nesta.org.uk/documents/impacts_of_innovation_policy_ synthesis_and_conclusion_final.pdf

Edquist, C., \& Johnson, B. H. (1997). Institutions and organizations in systems of innovation. In C. Edquist (Ed.), Systems of innovation: Technologies, institutions and organizations (pp. 41-63). London: Pinter. Retrieved from: https://www. researchgate.net/publication/246482165

Egbunike, O. (2016). State of the innovation. Newable News. Retrieved from: https://www.newable.co.uk/news-and-views/840433299/state-of-theinnovation.-by-obi-egbunike-innovation-advisor-newable.php

European Commission. (2014). National/regional innovation strategies for smart specialisation (RIS3). Brussels: European Commission. Retrieved from: https://ec.europa.eu/regional_policy/sources/docgener/informat/2014/smart_ specialisation_en.pdf

European Space Agency (ESA). (2019). Copernicus Masters. Retrieved from: https://www.copernicus-masters.com/

Farole, T., Rodríguez-Pose, A., \& Storper, M. (2010). Human geography and the institutions that underlie economic growth. Progress in Human Geography, 35(1), 58-80. doi: https://doi.org/10.1177/0309132510372005

Flanagan, K., \& Uyarra, E. (2016). Four dangers in innovation policy studies and how to avoid them. Industry and Innovation, 23(2), 177-188. doi: https:// doi.org/10.1080/13662716.2016.1146126

Flanagan, K., Uyarra, E., \& Laranja, M. (2011). Reconceptualising the "policy mix" for innovation. Research Policy, 40(5), 702-713. doi: https://doi. org/10.1016/j.respol.2011.02.005

Foray, D., \& Goenaga, X. (2013). The goals of smart specialisation. Luxembourg: Publications Office of the European Union. Retrieved from: https://publications. europa.eu/en/publication-detail/-/publication/225c8ada-7295-46b7-8711714cca360b04/language-en 
Gianelle, C., Kyriakou, D., Cohen, C., \& Przeor, M. (Eds.). (2016). Implementing smart specialisation strategies: A handbook. Brussels: European Commission. doi: https://doi.org/10.2791/53569

Grillitsch, M. (2016). Institutions, smart specialisation dynamics and policy. Environment and Planning C: Government and Policy, 34, 22-37. doi: https://doi. org/10.1177/0263774X15614694

Hannon, M. J., Skea, J., \& Rhodes, A. (2014, August). Facilitating and coordinating UK energy innovation through systemic innovation intermediaries. Paper presented at the $5^{\text {th }}$ International Conference on Sustainability Transitions, Utrecht.

Hartley, J. (2004). Case study research. In C. Cassell \& G. Symon (Eds.), Essential guide to qualitative methods in organizational research (pp. 323-333). London: SAGE Publications. doi: https://doi.org/10.4135/9781446280119.n26

Hausmann, R., \& Rodrik, D. (2003). Economic development as self-discovery. Journal of Development Economics, 72(2), 603-633. doi: https://doi.org/10.1016/ S0304-3878(03)00124-X

HM Government. (2017). Industrial strategy: Building a Britain fit for the future. London: HM Government. Retrieved from: www.gov.uk/government/ publications

Howells, J. (2006). Intermediation and the role of intermediaries in innovation. Research Policy, 35(5), 715-728. doi: https://doi.org/10.1016/j. respol.2006.03.005

Hyysalo, S., \& Stewart, J. (2008). Intermediaries, users and social learning in technological innovation. International Journal of Innovation Management, 12(3), 295-325. doi: https://doi.org/10.1142/S1363919608002035

Jolly, S. (2006). A Europe of regions: Regional integration, sub-national mobilisation and the optimal size of states. (Doctoral dissertation). Duke University, Durham, NC. Retrieved from: https://sethkjolly.com/files/diss.pdf 
Karo, E., \& Kattel, R. (2015). Economic development and evolving state capacities in Central and Eastern Europe: Can "smart specialization" make a difference? Journal of Economic Policy Reform, 18(2), 172-187. doi: https://doi.or $\mathrm{g} / 10.1080 / 17487870.2015 .1009068$

Karo, E., \& Kattel, R. (2016). How to organize for innovation: Entrepreneurial state and organizational variety. Working Papers in Technology Governance and Economic Dynamics No. 66. Retrieved from: http://hum.ttu.ee/wp/paper66.pdf

Karo, E., Kattel, R., \& Cepilovs, A. (2017). Can smart specialization and entrepreneurial discovery be organized by the government? Lessons from Central and Eastern Europe. In S. Radosevic et al. (Eds.), Advances in the theory and practice of smart specialization (pp. 269-292). Academic Press. doi: https://doi. org/10.1016/B978-0-12-804137-6.00013-9

Karo, E., \& Looga, L. (2016). Understanding institutional changes in economic restructuring and innovation policies in Slovenia and Estonia. Journal of International Relations and Development, 19(4), 500-533. doi: https://doi. org/10.1057/jird.2014.23

Katzy, B., Turgut, E., Holzmann, T., \& Sailer, K. (2013). Innovation intermediaries: A process view on open innovation coordination. Technology Analysis and Strategic Management, 25(3), 295-309. doi: https://doi.org/10.1080/09537325.2013.76 4982

Kerry, C., \& Danson, M. (2016). Open innovation, triple helix and regional innovation systems. Industry and Higher Education, 30(1), 67-78. doi: https:// doi.org/10.5367/ihe.2016.0292

Kilelu, C. W., Klerkx, L., Leeuwis, C., \& Hall, A. (2011). Beyond knowledge brokering: An exploratory study on innovation intermediaries in an evolving smallholder agricultural system in Kenya. Knowledge Management for Development Journal, 7(1), 84-108. doi: https://doi.org/10.1080/19474199.2011.593859 
Kim, E. S. (2015). Facilitating innovation in SMEs: The case of public intermediaries in South Korea. (Doctoral dissertation). The University of Edinburgh, Edinburgh. Retrieved from: https://www.era.lib.ed.ac.uk/bitstream/handle/1842/19543/ Kim2015.pdf?sequence $=2 \&$ isAllowed $=y$

Kivimaa, P. (2014). Government-affiliated intermediary organisations as actors in system-level transitions. Research Policy, 43(8), 1370-1380. doi: https://doi. org/10.1016/j.respol.2014.02.007

Klein Woolthuis, R., Lankhuizen, M., \& Gilsing, V. (2005). A system failure framework for innovation policy design. Technovation, 25(6), 609-619. doi: https://doi.org/10.1016/J.TECHNOVATION.2003.11.002

Klerkx, L., \& Leeuwis, C. (2008). Matching demand and supply in the agricultural knowledge infrastructure: Experiences with innovation intermediaries. Food Policy, 33(3), 260-276. doi: https://doi.org/10.1016/J.FOODPOL.2007.10.001

Kokshagina, O., Le Masson, P., Kazakci, A., \& Bories, F. (2015, June). Fastconnecting open innovation practices: On the role of intermediaries to accelerate the absorptive capacity function. Paper presented at the $26^{\text {th }}$ ISPIM Conference: Shaping the Frontiers of Innovation Management, Budapest. Retrieved from: http://search.proquest.com/openview/7a3a28ef95c7ba7967b826486ad369b0/1 ?pq-origsite $=$ gscholar $\& \mathrm{cbl}=1796422$

Kotnik, P., \& Petrin, T. (2017). Implementing a smart specialisation strategy: An evidence-based approach, International Review of Administrative Sciences, 83(1), 85-105. doi: https://doi.org/10.1177/0020852315574994

Kroll, H. (2015). Efforts to implement smart specialization in practice-Leading unlike horses to the water. European Planning Studies, 23(10), 2079-2098. doi: https://doi.org/10.1080/09654313.2014.1003036

Kroll, H. (2019). Eye to eye with the innovation paradox: Why smart specialization is no simple solution to policy design. European Planning Studies, 27(5), 932951. doi: https://doi.org/10.1080/09654313.2019.1577363

Leach, N. (2014). Terrestrial space architecture. Architectural Design, 84(6), 5463. doi: https://doi.org/10.1002/ad.1833 
Lee, S., Park, G., Yoon, B., \& Park, J.-W. (2010). Open innovation in SMEs: An intermediated network model. Research Policy, 39(2), 290-300. doi: https://doi. org/10.1016/j.respol.2009.12.009

Lombardi, E. (2016). The organisation of the space sector in Italy: A focus on the Lazio region. Retrieved from: https://www.academia.edu/31526574/THE_ ORGANISATION_OF_THE_SPACE_SECTOR_IN_ITALY_A_focus_on_ the_Lazio_Region

London Economics. (2015). Development of the Scottish space industry. London: London Economics. Retrieved from: https://www.space-network.scot/images/ downloads/reports/LE_SE_Scottish_Space_Industry.pdf

Lukkarinen, J., Berg, A., Salo, M., Tainio, P., Alhola, K., \& Antikainen, R. (2018). An intermediary approach to technological innovation systems (TIS) The case of the cleantech sector in Finland. Environmental Innovation and Societal Transitions, 26, 136-146. doi: https://doi.org/10.1016/j.eist.2017.04.003

Macdonald, K. (2017, January 31). Scottish space industry soaring high. $B B C$ News. Retrieved from: http://www.bbc.co.uk/news/38804310

Macdonald, M. (2019, February 26). State of the nation's space sector. Retrieved from: https://medium.com/@malcoluim/state-of-the-scottish-nations-spacesector-faead692c979

Martin, S., Pahor, M., \& Jaklič, M. (2015). The structure of policy-induced innovation networks in Slovenia. European Journal of Innovation Management, 18(4), 428-450. doi: https://doi.org/10.1108/EJIM-09-2013-0093

Martin, S., \& Scott, J. T. (2000). The nature of innovation market failure and the design of public support for private innovation. Research Policy, 29(4-5), 437447. doi: https://doi.org/10.1016/S0048-7333(99)00084-0

Mastroeni, M., Omidvar, O., Rosiello, A., Tait, J., \& Wield, D. (2017). Science and innovation dynamics and policy in Scotland: The perceived impact of enhanced autonomy. International Journal of Technology Management \& Sustainable Development, 16(1), 3-24. doi: https://doi.org/10.1386/tmsd.16.1.3_1 
McCann, P., \& Ortega-Argilés, R. (2014). Smart specialisation in European regions: Issues of strategy, institutions and implementation. European Journal of Innovation Management, 17, 583-596. doi: https://doi.org/10.1108/EJIM-052014-0052

McCann, P., \& Ortega-Argilés, R. (2015). Smart specialization, regional growth and applications to European Union cohesion policy. Regional Studies, 49(8), 1291-1302. doi: https://doi.org/10.1080/00343404.2013.799769

Mgumia, A. H., Mattee, A. Z., \& Kundi, B. A. T. (2015). Contribution of innovation intermediaries in agricultural innovation: The case of agricultural R\&D in Tanzania. African Journal of Science, Technology, Innovation and Development, 7(2), 151-160. doi: https://doi.org/10.1080/20421338.2015.1023644

Morgan, K. (2017). Nurturing novelty: Regional innovation policy in the age of smart specialisation. Environment and Planning C: Politics and Space, 35(4), 569-583. doi: https://doi.org/10.1177/0263774X16645106

Nilsson, M., \& Sia-Ljungström, C. (2013). The role of innovation intermediaries in innovation systems. System Dynamics and Innovation in Food Networks 2013: Proceedings of the $\sigma^{\text {th }}$ International European Forum on System Dynamics and Innovation in Food Networks, 161-180. Retrieved from: https://ideas.repec.org/p/ ags/iefi13/164741.html

Nishimura, J., \& Okamuro, H. (2011). Subsidy and networking: The effects of direct and indirect support programs of the cluster policy. Research Policy, 40(5), 714-727. doi: https://doi.org/10.1016/J.RESPOL.2011.01.011

Organisation for Economic Co-operation and Development (OECD). (2004). Promoting entrepreneurship and innovative SMEs in a global economy: Towards a more responsible and inclusive globalisation. $2^{\text {nd }}$ OECD Conference of Ministers Responsible for Small and Medium-Sized Enterprises (SMEs), p. 59.

Organisation for Economic Co-operation and Development (OECD). (2007). The space economy at a glance 2007. Paris: OECD Publishing. doi: https:/doi. org/10.1787/9789264040847-en 
Organisation for Economic Co-operation and Development (OECD). (2011). ISIC Rev. 3 technology intensity definition: Classification of manufacturing industries into categories based on $R \& D$ intensities. OECD Directorate for Science, Technology and Industry, Economic Analysis and Statistics Division.

Organisation for Economic Co-operation and Development (OECD). (2013). Innovation-driven growth in regions: The role of smart specialisation. Paris: OECD. Retrieved from: https://www.oecd.org/innovation/inno/smart-specialisation.pdf

Organisation for Economic Co-operation and Development (OECD). (2014). The space economy at a glance 2014. Paris: OECD Publishing. doi: https://doi. org/10.1787/9789264217294-en

Parikh, M. (2001). Knowledge management framework for high-tech research and development. Engineering Management Journal, 13(3), 27-34. doi: https:// doi.org/10.1080/10429247.2001.11415124

Polverari, L. (2016). The Implementation of smart specialisation strategies in 2014-20 ESIF programmes: Turning intelligence into performance. IQ-Net Thematic Paper 39(2). Glasgow: European Policies Research Centre.

Radosevic, S., \& Myrzakhmet, M. (2009). Between vision and reality: Promoting innovation through technoparks in an emerging economy. Technovation, 29(10), 645-656. doi: https://doi.org/10.1016/J.TECHNOVATION.2009.04.001

Regulation (EC) No. 1059/2003 of the European Parliament and of the Council of 26 May 2003 on the establishment of a common classification of territorial units for statistics (NUTS). (2018). Official Journal of the European Union, L 154. Retrieved from: https://eur-lex.europa.eu/legal-content/EN/ ALL/?uri=CELEX:02003R1059-20180118\&qid=1519136585935

Reid, A., \& Maroulis, N. (2017). From strategy to implementation: The real challenge for smart specialization policy. In S. Radosevic et al. (Eds.), Advances in the theory and practice of smart specialization (pp. 293-318). Academic Press. doi: https://doi.org/10.1016/B978-0-12-804137-6.00012-7 
Reid, A., \& Stanovnik, P. (2013). The development of a Smart Specialisation Strategy (S3) for Slovenia: A report to the European Commission, DG Research \& Innovation. doi: https://doi.org/10.13140/RG.2.2.30434.32962

Republic of Slovenia. (2017). Slovenia's Smart Specialisation Strategy S4. Ljubljana: Government Office for Development and European Cohesion Policy. Retrieved from: http://www.svrk.gov.si/fileadmin/svrk.gov.si/pageuploads/Dokumenti_za_ objavo_na_vstopni_strani/S4_dokument_V_2017EN.pdf

Rodríguez-Pose, A. (2013). Do institutions matter for regional development? Regional Studies, 47(7), 1034-1047. doi: https://doi.org/10.1080/00343404.20 12.748978

Rodríguez-Pose, A., di Cataldo, M., \& Rainoldi, A. (2014). The role of government institutions for smart specialisation and regional development. JRC Technical Reports, S3 Policy Brief Series No. 04/2014. Luxembourg: Publications Office of the European Union.

Satellite Applications Catapult. (2014). Satellites: The bigpicture. Harwell: Satellite Applications Catapult. Retrieved from: https://cpb-us-e1.wpmucdn.com/blogs. rice.edu/dist/5/1410/files/2014/12/S4E_Brochure_Amended_Version_2_lo_ res2.pdf

Science and Technology Facilities Council (STFC). (2013). Higgs theory gains "mass"! Retrieved from: https://stfc.ukri.org/news/higgs-theory-gainse2809cmasse2809d/

Science and Technology Facilities Council (STFC). (2015). The Higgs Centre for Innovation. Retrieved from: https://stfc.ukri.org/innovation/campuses/businessincubation/the-higgs-centre-for-innovation/

Science and Technology Facilities Council (STFC). (2018). Higgs Centre for Innovation. Retrieved from: http://www.roe.ac.uk/higgscentre/

Scottish Business Insider. (2018, December). Why Space plc is now the Scottish frontier. Retrieved from: https://www.insider.co.uk/special-reports/spacesatellites-industry-scotland-gsi-13762109 
Seidel, U., Müller, L., Köcker, G. M., \& Filho, G. de A. (2013). A new approach for analysing national innovation systems in emerging and developing countries. Industry and Higher Education, 27(4), 297-285.

Space IGS. (2011). The space innovation and growth strategy: Main report. Retrieved from: https://www.ukspace.org/wp-content/uploads/2019/03/Space-IGS-MainReport_Feb2010.pdf

Space IGS. (2014). Space growth action plan. Retrieved from: https://www.gov.uk/ government/publications/space-growth-action-plan

Stare, M., Bucar, M., \& Udovic, B. (2014). Soustvarjanje znanja med javnimi raziskovalnimi organizacijami in gospodarstvom za povecanje konkurencnosti. IB Revija, 3-4, 53-59.

The Scottish Government. (2015). European Structural Funds: A smart, sustainable and inclusive Scotland in Europe. Retrieved from: https:/www.gov.scot/ publications/european-structural-funds-smart-sustainable-inclusive-scotlandeurope/pages/9/

Uranjek, E. (2019). Kaj ima Slovenija od tega, da Evropski vesoljski agenciji plačuje 2,5 milijona evrov letno? MMC RTV SLO. Retrieved from: https://www. rtvslo.si/znanost-in-tehnologija/kaj-ima-slovenija-od-tega-da-evropski-vesoljskiagenciji-placuje-2-5-milijona-evrov-letno/481004

Valdaliso, J. M., Magro, E., Navarro, M., Aranguren, M. J., \& Wilson, J. R. (2014). Path dependence in policies supporting smart specialisation strategies: Insights from the Basque case. European Journal of Innovation Management, 17(4), 390-408. doi: https://doi.org/10.1108/EJIM-12-2013-0136

Vanthillo, T., \& Verhetsel, A. (2012). Paradigm change in regional policy: Towards smart specialisation? Lessons from Flanders (Belgium). Belgeo: Belgian Journal of Geography, 1-2. doi: https://doi.org/10.4000/belgeo.7083

Vidmar, M. (2018, June). Building a functional typology of innovation intermediaries' interventions. Paper presented at the DRUID 2018 Conference, Copenhagen. Retrieved from: https://conference.druid.dk/acc_papers/ gpge9gxi0gabcivnep4vgp4ein1cd9.pdf 
Vidmar, M. (2019a). Agile Space Living Lab - The emergence of a new hightech innovation paradigm. Space Policy, 49. doi: https://doi.org/10.1016/j. spacepol.2019.05.002

Vidmar, M. (2019b, October). Enablers, equippers, shapers and movers: A typology of innovation intermediaries interventions and the development of an emergent innovation system. Paper presented at the International Astronautical Congress, Washington, DC.

Vidmar, M. (2019c). Space innovation policy: Building a "New Space" economy in the Scotland's "Space Glen". Manuscript submitted for publication.

Willetts, D. (2013). Eight great technologies. London: Policy Exchange.

Wilson, K. (2007). Encouraging the internationalisation of SMEs. In J. Potter \& A. Proto (Eds.), Promoting entrepreneurship in South East Europe: Policies and tools (pp. 43-66). Paris: OECD. Retrieved from: http://www.gvpartners.com/web/ pdf/Chapter_2_Wilson_FINAL.pdf

Woodcock, C. E., Allen, R., Anderson, M., Belward, A., Bindschadler, R., Cohen, W., Gao, F., Goward, S. N., Helder, D., Helmer, E., Nemani, R., Oreopoulos, L., Schott, J., Thenkabail, P. S., Vermote, E. F., Vogelmann, J., Wulder, M. A., Wynne, R. (2008). Free access to Landsat imagery [Letter]. Science, 320(5879), p. 1011. doi: https://doi.org/10.1126/science.320.5879.1011a

Wostner, P. (2017). From projects to transformations: Why do only some countries and regions advance? The case of the Slovenian S4. European Structural and Investment Funds Journal, 5(1), 84-96. Retrieved from: https://estif.lexxion. eu/article/estif/2017/1/11/display/html

Yin, R. K. (2009). Case study research: Design and methods. London: Sage Publishing. 